\title{
A simulation experiment study to examine the effects of noise on miners' safety behavior in underground coal mines
}

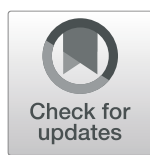

\author{
Jing Li, Yaru Qin* ${ }^{*}$, Lei Yang, Zhen Wang, Ke Han and Cheng Guan
}

\begin{abstract}
Background: Noise pollution in coal mines is of great concern. Personal injuries directly or indirectly related to noise occur from time to time. Its effects impact the health and safety of coal mine workers. This study aimed to identify if and how the level of noise impacts miners' safety behavior in underground coal mines.

Methods: In order to study the influence of noise on miners in the mining industry, we built a coal mine noise simulation experiment system, and set the noise test level at $50 \mathrm{~dB} \sim 120 \mathrm{~dB}$ according to the actual working environment at well. We divided the noise gradient into 8 categories and conducted 93 experiments, in which we aim to test miners' attention distribution, fatigue, and reaction under each level, and the experimental results were analyzed by SPSS22.0 software.

Results: The results show that the increase of environmental noise level will have an impact on the attention, reaction, and fatigue. The noise is positively related to the fatigue, the noise is negatively related to the attention and reaction. In the noise environment, the sensitivity of the personnel to optic stimuli is higher than that to acoustic stimuli. The test indicators of attention, fatigue, and reaction will change significantly, when the noise level is greater than $70 \sim 80 \mathrm{~dB}$.

Conclusions: From the perspective of accident prevention, the noise level can be controlled within the range of less than $70 \sim 80 \mathrm{~dB}$, which can control the occurrence of accidents to a certain extent.
\end{abstract}

Keywords: Coal mine noise, Safety behavior ability, Attention distribution, Reaction, Fatigue

\section{Background}

Coal mine production accidents occur frequently to China. Accident statistical analysis shows that $96.5 \%$ coal mine accidents were caused by human errors [1]. Coal mine noise is one of the important causes of human errors. It comes from industrial equipment in production activities [2], such as shearers, tunneling machines, ventilators, conveyors, rock drills, pneumatic drills, etc. [3] Also, noise from underground coal mine has multiple sound sources, high intensity, high sound level, and frequency

\footnotetext{
* Correspondence: qinyaru66@126.com

College of emergency management and safety engineering, China University of Mining and Technology, Beijing, China
}

bandwidth [4]. Relevant data [3, 4] and previous field research findings revealed that the noise level in most underground mine operating environment has reached more than $90 \mathrm{~dB}$. This figure exceeds $85 \mathrm{~dB}$ (Work $5 \mathrm{~d}$ a week, $8 \mathrm{~h}$ a day, the steady-state noise limit is $85 \mathrm{~dB}(\mathrm{~A})$ ), the maximum health limit in the "Occupational Exposure Limits for Hazardous Agents in The Workplace - Physical Factors" (GBZ2.2-2007) [5]. Coal mine noise negative impacts on miners' psychology, physiology, and behavior, affecting coal mine safety production $[4,6,7]$.

Psychologically, noise impacts people's mood and is likely to produce irritability [8].

(c) The Author(s). 2021 Open Access This article is licensed under a Creative Commons Attribution 4.0 International License, which permits use, sharing, adaptation, distribution and reproduction in any medium or format, as long as you give appropriate credit to the original author(s) and the source, provide a link to the Creative Commons licence, and indicate if changes were made. The images or other third party material in this article are included in the article's Creative Commons licence, unless indicated otherwise in a credit line to the material. If material is not included in the article's Creative Commons licence and your intended use is not permitted by statutory regulation or exceeds the permitted use, you will need to obtain permission directly from the copyright holder. To view a copy of this licence, visit http://creativecommons.org/licenses/by/4.0/ The Creative Commons Public Domain Dedication waiver (http://creativecommons.org/publicdomain/zero/1.0/) applies to the data made available in this article, unless otherwise stated in a credit line to the data. 
Physiologically, scholars have conducted a lot of researches on how noise affects hearing, heart rate, and blood pressure. Noise affects human auditory organs, nervous system, and cardiovascular system, etc. [9-14]. Basner et al. [15] studied the effects of noise on hearing, and found hearing loss caused by noise is very common in working environments. Studies [16-22] have also found that high noise levels can cause hearing loss and general health problems. Masterson et al. [23] studied the hearing loss of workers exposed to noise from 2003 to 2012 and found $76 \%$ mining workers are exposed to dangerous noise. It was the highest among all industries. They suffered most from hearing impairment among all industries. Early researches [24, 25] found blood pressure and heart rate increase in long-term exposure to noise. Tian et al. [26] found subjects' heart rate would increase in noise environment. Scholars have also explored the relationship between noise and blood pressure, and their conclusions varied about whether and how noise affects blood pressure. Hessel et al. [27] found that occupational noise exposure had no effect on blood pressure. However, Liu et al. [28] suggests that noise in working environment contributes to hypertension and can increase systolic and diastolic blood pressure.

Coal mine noise affects the safety behavior of miners and causes safety accidents. Current researches show that noise in the workplace has a significant impact on the behavior of workers [4, 29-32]. Behavior refers to the physical, psychological, and action responses to external stimuli. As an external stimulus, noise changes people's physiology, psychology, and actions, and affects people's behavior. Cheng et al. [6] studied how coal mine noise affects physiology and psychology of miners, and the impact of noise on human safety behavior. They found that noise has a serious negative effect on the miners' safety behavior. Deng [33] states that noise has an impact on physiology and psychology, and then affects human behavior and leads to safety accidents. Yu et al. [34] compared the accidents in two factories, and found accidents in a $95 \mathrm{~dB}$ are significantly more than in $80 \mathrm{~dB}$; accidents in a noisy environment is 20 times higher than in a quiet environment. Wang et al. [35] studied how noise influences miners' behavior ability, and found the behavior ability of miners in a strong noise environment of $85 \mathrm{~dB}$ and $95 \mathrm{~dB}$ is significantly lower than in lower noise environments. Some of these studies found that $[36,37]$ noise impacts human attention, and noise above $85 \mathrm{~dB}$ would have a greater negative impact on human attention. Reaction time would prolong under strong noise [38]. Tian et al. [29] compared two groups of workers. One group has more knowledge and better awareness about safety production than the other group. The study found that noise has a greater impact on miners with a lower level of knowledge and awareness about safety production.
In general, attention, reaction, and fatigue are three most often studied behavioral ability indicators. Attention means the ability to focus. Attention distribution ability is how accurate to conduct multiple tasks at the same time. In other words, it means how well one can pay attention to different objects at the same time. When workers operate the equipment continuously for a long time, they are often fatigue and their working efficiency decrease [39]. Reaction ability means the response to stimuli signals. First, stimuli are felt by nerve system. Then, it is transmitted from the nerve system to the brain. Brain processes the stimuli and produces instructions to the muscles via nerve system and directs muscle contraction. Reaction ability is evaluated by the reaction time to the stimuli, the time duration from the moment when the external stimulus is received by the nerve system to the completion of reactive behavior by muscles [31]. In addition, noise is commonly believed to be positively correlated with fatigue [40]. Fatigue is often measured by the flicker fusion frequency. And the lower the flash fusion frequency is, the more fatigue the human body are [40]. When being fatigue, people will slow down their thinking and movements, lose concentration. In this case, coordination and accuracy of movements decline and safety behavior ability reduces [41].

The above researches on the impact of noise on people mainly focus on occupational hazards, and relatively little researches has been conducted on the effects of noise on human behavior. However, most of the above studies regard noise as an overall influencing factor, and they haven't divided noise into different levels. Very few of them studied on simulation experiments of real noise environment in coal mines. Therefore, we aimed to explore the relationship between noise changes and miners' behavior ability changes. To do this, this paper built an independent coal mine noise simulation experiment system, and divided the noise data collected in the real coal mine into 8 levels, and studied how 8 noise levels influence the safety behavior of miners in terms of attention, reaction, and fatigue. We hope this study could provide new ideas for underground coal mine noise prevention and coal mine accident prevention.

\section{Methods}

In this quantitative research, attention, reaction, and fatigue are selected as research indicators after referring to the relevant literature $[26,42,43]$.

\section{Experimental system design}

The experimental system consists of a noise control system and a safety behavior ability testing system.

The noise control system consists of noise source, a louder speaker box, a sound meter, and a computer. The noise from the underground coal mine is collected as 
the noise source. The noise levels are precisely controlled through the louder speaker box and the sound meter.

The safety behavior ability testing system consists of an attention distribution meter, a multiple reaction meter, and a flicker frequency fusion meter. They test the changes in attention, reaction, and fatigue level on 8 noise levels. The specific description is as follows.

\section{Attention}

The experiment selected BD-II-314 attention distribution meter, to measure the subjects' attention distribution. The meter tested subjects' ability to perform two tasks at the same time. $Q$ value of attention distribution was used to indicate attention distribution. It is calculated by Eq. 1 :

$$
Q=\sqrt{\left(S_{2} / S_{1}\right) \times\left(F_{2} / F_{1}\right)}
$$

Note: $S_{1}$ indicates the times of correct reactions to acoustic stimuli; $S_{2}$ indicates the total times of reactions to the acoustic stimuli; $F_{1}$ indicates the times of correct reactions to optic stimuli; $F_{2}$ indicates the total times of reactions to optic stimuli.

The meaning of $\mathrm{Q}$ value is as follows:

When $\mathrm{Q}<0.5$, there is no attention distribution value; When $0.5 \leq \mathrm{Q}<1.0$, only a part of the total attention is assigned;

When $\mathrm{Q}=1.0$, the attention distribution value reaches the highest level. It means the efficiency of performing multiple tasks simultaneously is equal to the efficiency when doing a single task.

When $\mathrm{Q}>1.0$, the attention distribution value is invalid.

\section{Reaction ability}

In our study, we used BD-II-509B multiple reaction time tester to measure the reaction ability of the subjects to acousto-optic stimuli.

\section{Fatigue}

This study used the BD-II-118 flicker frequency fusion meter to measure the critical flicker fusion frequency of the subjects.
The noise test equipment is shown in Table 1.

There are 8 noise levels in our tests, one control group and seven experimental groups. The noise level of control group was $50 \mathrm{~dB}$. The seven experimental groups were $60 \mathrm{~dB}$ group, $70 \mathrm{~dB}$ group, $80 \mathrm{~dB}$ group, $90 \mathrm{~dB}$ group, $100 \mathrm{~dB}$ group, $110 \mathrm{~dB}$ group, and $120 \mathrm{~dB}$ group. This is because through reviewing the literature and onsite investigation, we found the range of underground coal mine noise is mainly between $90 \mathrm{~dB}$ and $120 \mathrm{~dB}$ $[4,6]$. Also, this experiment also set 4 noise levels below $90 \mathrm{~dB}$ to explore the influence of a wider range of noise on workers' safety behavior ability in order to improve the credibility of the experimental results.

The subjects of this study are healthy male graduate and undergraduate students aged from 20 to 25. During the experiment, the subjects did not use any personal protective equipment. In the early stage of the experiment, 14 subjects were selected to conduct experimental tests with 5 noise levels $(50 \mathrm{~dB}, 60 \mathrm{~dB}, 70 \mathrm{~dB}, 80 \mathrm{~dB}$, and $90 \mathrm{~dB}$ ). But 1 of 14 subjects had tinnitus in the $90 \mathrm{~dB}$ environment. In the later stage, 8 subjects were selected from the former 14 subjects to conduct tests with 100 $\mathrm{dB}, 110 \mathrm{~dB}$, and $120 \mathrm{~dB}$ to meet the consistency of the noise intensity of the test and the real noise environment in the coal mine.

In this study: the fatigue level was measured by the flicker fusion critical frequency; the subject's attention level was measured by their distinguishing different sound and light; the reaction ability was tested by the subject's reaction time to sound and light. The safety behavioral testing system equipment is shown in Fig. 1.

\section{Experimental steps}

The experiment was divided into two stages, before the experiment and while experimenting.

Preparation before the experiment was as follows: (a) The subjects were told about the test procedure, and trained to use the instrument so that they can operate the instrument, understand the content of the questionnaire and minimize any unnecessary errors; (b) Keep the environmental conditions in advance, including temperature, humidity, and wind speed at a normal level and debugging the equipment. During the whole test period, the subjects should maintain adequate sleep (Not less than $8 \mathrm{~h}$ [44]).

Table 1 Noise test equipment

\begin{tabular}{lllll}
\hline Experiment System & Device Name & Equipment Model & Manufacturer & Certification Information \\
\hline Noise Control System & Computer & Dell- inspiron 7557 & & \\
& Louder Speaker Box & JBL- Charge4 & & \\
& Sound Meter & TES1350A & & ISO9001: 2015 quality \\
Safety Working Ability & Attention Distribution Meter & BD- II-314 & Beijing Qingniao Tianqiao & Instrument Equipment Co., Ltd. \\
Testing System & Multiple Reaction Time Tester & BD- II-509B & & certification \\
& Flicker Frequency Fusion Meter & BD- II-118 & \\
\hline
\end{tabular}




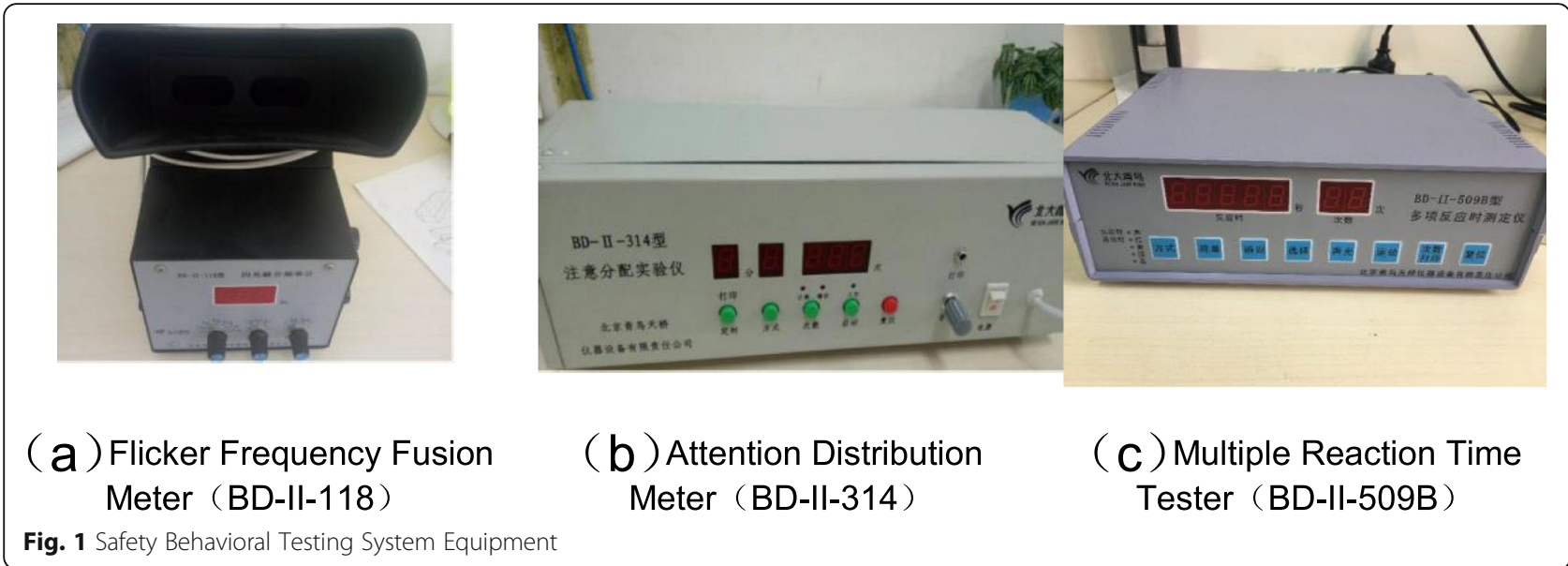

The experimental operation involved eight different noise levels. In order to study subjects' safety behavior ability in each noise level, 14 subjects were divided into seven groups with two subjects in each group (due to the capacity of the experiment devices) in the $50 \sim 90$ $\mathrm{dB} ; 8$ subjects were divided into 4 groups with two subjects in each group (due to the capacity of the experiment devices) in $100 \mathrm{~dB}, 110 \mathrm{~dB}$, and $120 \mathrm{~dB}$. The test process of one noise level was as follows: First, subjects in a group entered the test environment with a certain noise level, and adapted to the environment for $30 \mathrm{~min}$. Then, their fatigue, attention, and reaction were tested for $30 \mathrm{~min}$ and the data were collected. When this group finished, other groups came in the test room one by one and all the data on this noise level were collected. Notably, the numbers of errors made and the reaction time of subjects were recorded synchronously. In general, the whole process for one group of subjects (two people) lasted for $1 \mathrm{~h}$; the actual test time of seven groups of subjects in the $50 \sim 90 \mathrm{~dB}$ (altogether 14 people) for each specific noise condition lasted for $7 \mathrm{~h}$ in total in a day; the actual test time of four groups of subjects in the $100 \sim 120 \mathrm{~dB}$ (altogether 8 people) for each specific noise condition lasted for $4 \mathrm{~h}$ in total in a day. The eight different noise conditions were tested on 8 different days, during generally the same period of daytime.

\section{Statistical analysis methods}

This study mainly used two statistical analysis methods: paired-sample $\mathrm{t}$-test and regression analysis. Pairedsample t-test aims to compare the influence difference of two noise levels on human's safe behavior ability. Specifically, seven experimental groups $(60 \mathrm{~dB}, 70 \mathrm{~dB}, 80$ $\mathrm{dB}, 90 \mathrm{~dB}, 100 \mathrm{~dB}, 110 \mathrm{~dB}$, and $120 \mathrm{~dB}$ ) were performed paired t-tests respectively with control group $(50 \mathrm{~dB})$ and to see if there is a significant difference between the experimental group and the control group, and to find on which noise level workers' safety behavior may change significantly. To make paired-sample t-test valid, an exploratory analysis of the data is required to determine whether it conforms to a normal distribution before pairedsample t-test. Regression analysis aims to research relevance between independent variable (noise) and dependent variable (attention, reaction, and fatigue). In short, this study firstly studied whether noise affects human safety behavior (attention, reaction, and fatigue), and if so, how does it affect (positively or negatively).

\section{Result}

\section{Attention}

\section{Exploratory analysis}

As is shown in Table 2, the significant $p$-value of the S$\mathrm{W}$ test of the acousto-optic reaction correct times and that of the $Q$ values were both greater than 0.05 in all 8 noise levels. This presents a normal distribution, and thus paired sample t-test can be performed.

\section{Sample analysis of $t$-test}

As is shown in Tables 3 and 4, the correct times of the acoustic reactions, the optic reactions and the $\mathrm{Q}$ values in the control groups were significantly different from the test values of the control group in $80 \mathrm{~dB}$ and above $(P<0.05)$. That is, when the noise is $80 \mathrm{~dB}$ or above, the attention level starts to change significantly compared with the control group $(50 \mathrm{~dB})$.

\section{Reaction ability \\ Exploratory analysis}

Table 5 shows the results of the normality test of the reaction time. From the S-W test in the table, we can see $p>0.05$. This indicates the reaction time of the acousto-optic is normally distributed on 8 noise levels. Therefore, paired sample t-test can be used to analyze the influence of different noise levels on the reaction time. 
Table 2 Exploratory analysis results of attention distribution data

\begin{tabular}{|c|c|c|c|c|}
\hline \multirow[t]{2}{*}{ Test items } & & \multicolumn{3}{|c|}{ Shapiro-Wilk } \\
\hline & & Statistics & df & Significant $p$ \\
\hline \multirow[t]{3}{*}{ Control } & The number of correct reaction to sound & .984 & 14 & .991 \\
\hline & The number of correct reaction to light & .961 & 14 & .740 \\
\hline & Q value & .966 & 14 & .802 \\
\hline \multirow[t]{3}{*}{ Noise $60 \mathrm{~dB}$} & The number of correct reaction to sound & .968 & 14 & .848 \\
\hline & The number of correct reaction to light & .945 & 14 & .479 \\
\hline & Q value & .964 & 14 & .799 \\
\hline \multirow[t]{3}{*}{ Noise $70 \mathrm{~dB}$} & The number of correct reaction to sound & .958 & 14 & .688 \\
\hline & The number of correct reaction to light & .977 & 14 & .954 \\
\hline & Q value & .951 & 14 & .525 \\
\hline \multirow[t]{3}{*}{ Noise $80 \mathrm{~dB}$} & The number of correct reaction to sound & .925 & 14 & .263 \\
\hline & The number of correct reaction to light & .949 & 14 & .543 \\
\hline & Q value & .944 & 14 & .509 \\
\hline \multirow[t]{3}{*}{ Noise $90 \mathrm{~dB}$} & The number of correct reaction to sound & .935 & 13 & .391 \\
\hline & The number of correct reaction to light & .947 & 13 & .560 \\
\hline & Q value & .955 & 13 & .591 \\
\hline \multirow[t]{3}{*}{ Noise $100 \mathrm{~dB}$} & The number of correct reaction to sound & .921 & 8 & .437 \\
\hline & The number of correct reaction to light & .979 & 8 & .959 \\
\hline & Q value & .951 & 8 & .525 \\
\hline \multirow[t]{3}{*}{ Noise $110 \mathrm{~dB}$} & The number of correct reaction to sound & .900 & 8 & .287 \\
\hline & The number of correct reaction to light & .914 & 8 & .380 \\
\hline & Q value & .928 & 8 & .440 \\
\hline \multirow[t]{3}{*}{ Noise $120 \mathrm{~dB}$} & The number of correct reaction to sound & .917 & 8 & .408 \\
\hline & The number of correct reaction to light & .977 & 8 & .946 \\
\hline & Q value & .934 & 8 & .505 \\
\hline
\end{tabular}

Table 3 Paired sample t-test results of correct times to sound and light stimuli

\begin{tabular}{|c|c|c|c|c|c|c|c|c|}
\hline & \multicolumn{5}{|c|}{ Pairing Difference } & \multirow[t]{3}{*}{$\mathbf{t}$} & \multirow{3}{*}{$\begin{array}{l}\text { Degree of } \\
\text { Freedom }\end{array}$} & \multirow{3}{*}{$\begin{array}{l}\text { Significant } \\
P \text { (Two-tailed) }\end{array}$} \\
\hline & \multirow{2}{*}{$\begin{array}{l}\text { Average } \\
\text { value (E) }\end{array}$} & \multirow{2}{*}{$\begin{array}{l}\text { Standard } \\
\text { Deviation }\end{array}$} & \multirow{2}{*}{$\begin{array}{l}\text { Standard } \\
\text { Error } \\
\text { Mean }\end{array}$} & \multicolumn{2}{|c|}{ 95\% Confidence Interval for the Difference } & & & \\
\hline & & & & Lower Limit & Upper Limit & & & \\
\hline Sound Control - $60 \mathrm{~dB}$ & .785 & 5.146 & 1.375 & -2.185 & 3.757 & .571 & 13 & .578 \\
\hline Sound Control - $70 \mathrm{~dB}$ & 1.285 & 9.769 & 2.611 & -4.355 & 6.926 & .492 & 13 & .631 \\
\hline Sound Control - $80 \mathrm{~dB}$ & 7.785 & 11.178 & 2.987 & 1.331 & 14.239 & 2.606 & 13 & .022 \\
\hline Sound Control - $90 \mathrm{~dB}$ & 11.461 & 10.829 & 3.003 & 4.917 & 18.005 & 3.816 & 12 & .002 \\
\hline Sound Control - $100 \mathrm{~dB}$ & 4.750 & 2.764 & .977 & 2.438 & 7.061 & 4.860 & 7 & .002 \\
\hline Sound Control - $110 \mathrm{~dB}$ & 8.125 & 3.270 & 1.156 & 5.390 & 10.859 & 7.027 & 7 & .000 \\
\hline Sound Control - $120 \mathrm{~dB}$ & 11.500 & 2.828 & 1.000 & 9.135 & 13.864 & 11.500 & 7 & .000 \\
\hline Light Control - $60 \mathrm{~dB}$ & -1.071 & 2.758 & .737 & -2.664 & .521 & -1.453 & 13 & .170 \\
\hline Light Control - $70 \mathrm{~dB}$ & 1.142 & 3.483 & .930 & -.868 & 3.153 & 1.228 & 13 & .241 \\
\hline Light Control - $80 \mathrm{~dB}$ & 4.928 & 3.852 & 1.029 & 2.704 & 7.152 & 4.787 & 13 & .000 \\
\hline Light Control - $90 \mathrm{~dB}$ & 8.153 & 5.096 & 1.413 & 5.074 & 11.233 & 5.768 & 12 & .000 \\
\hline Light Control - $100 \mathrm{~dB}$ & 4.250 & 1.281 & .453 & 3.178 & 5.321 & 9.379 & 7 & .000 \\
\hline Light Control - $110 \mathrm{~dB}$ & 7.125 & 2.100 & .742 & 5.369 & 8.880 & 9.596 & 7 & .000 \\
\hline Light Control - $120 \mathrm{~dB}$ & 10.000 & 2.618 & .925 & 7.810 & 12.189 & 10.801 & 7 & .000 \\
\hline
\end{tabular}


Table 4 Paired sample t-test results of attention distribution Q value

\begin{tabular}{|c|c|c|c|c|c|c|c|c|}
\hline & \multicolumn{5}{|c|}{ Pairing Difference } & \multirow[t]{3}{*}{$\mathbf{t}$} & \multirow{3}{*}{$\begin{array}{l}\text { Degree of } \\
\text { Freedom }\end{array}$} & \multirow{3}{*}{$\begin{array}{l}\text { Significant } \\
P \text { (Two-tailed) }\end{array}$} \\
\hline & \multirow[t]{2}{*}{ Average (E) } & \multirow{2}{*}{$\begin{array}{l}\text { Standard } \\
\text { Deviation }\end{array}$} & \multirow{2}{*}{$\begin{array}{l}\text { Standard } \\
\text { Error } \\
\text { Mean }\end{array}$} & \multicolumn{2}{|c|}{ 95\% Confidence Interval for the Difference } & & & \\
\hline & & & & Lower Limit & Upper Limit & & & \\
\hline Control - $60 \mathrm{~dB}$ & -1.061 & 2.758 & .737 & -2.664 & .521 & -1.453 & 13 & .170 \\
\hline Control - $70 \mathrm{~dB}$ & 1.146 & 3.483 & .930 & -.868 & 3.153 & 1.228 & 13 & .241 \\
\hline Control - $80 \mathrm{~dB}$ & 5.029 & 3.852 & 1.029 & 2.704 & 7.152 & 3.989 & 13 & .000 \\
\hline Control - $90 \mathrm{~dB}$ & 6.173 & 5.096 & 1.413 & 5.074 & 11.233 & 4.961 & 12 & .000 \\
\hline Control - $100 \mathrm{~dB}$ & 6.665 & 5.709 & 1.595 & 5.369 & 8.850 & 5.134 & 7 & .000 \\
\hline Control - $110 \mathrm{~dB}$ & 7.023 & 6.124 & 1.973 & 7.449 & 12.395 & 5.930 & 7 & .000 \\
\hline Control - $120 \mathrm{~dB}$ & 8.235 & 6.802 & 2.023 & 8.349 & 11.044 & 6.395 & 7 & .000 \\
\hline
\end{tabular}

\section{Sample analysis of t-test}

Table 6 shows that as the external noise level increases, the absolute value of $t$ gradually increases, and $t$ always shows a negative value. It indicates that the test acoustooptic reaction time gradually increases with the increase of noise level. In other words, the greater the noise level is, the more significantly reaction ability decline. When the noise level reaches $70 \mathrm{~dB}$, the reaction time of the subjects to the acoustic stimuli becomes significantly longer; after $80 \mathrm{~dB}$, the reaction time to the optic stimuli becomes significantly longer. These show that the subjects react to optic stimuli better than the acoustic stimuli in the same noise level.

Table 5 Exploratory analysis results of acoustic and optical reactions

\begin{tabular}{lllll}
\hline Test items & & \multicolumn{3}{l}{ Shapiro-Wilk } \\
\cline { 3 - 5 } & & Statistics & df & Significant $\boldsymbol{p}$ \\
\hline Control & Light & .954 & 14 & .628 \\
& Sound & .905 & 14 & .132 \\
$60 \mathrm{~dB}$ & Light & .930 & 14 & .302 \\
& Sound & .902 & 14 & .121 \\
$70 \mathrm{~dB}$ & Light & .946 & 14 & .499 \\
& Sound & .916 & 14 & .194 \\
$80 \mathrm{~dB}$ & Light & .946 & 14 & .506 \\
& Sound & .925 & 14 & .262 \\
$90 \mathrm{~dB}$ & Light & .962 & 13 & .780 \\
& Sound & .929 & 13 & .331 \\
$100 \mathrm{~dB}$ & Light & .875 & 8 & .169 \\
& Sound & .938 & 8 & .593 \\
$110 \mathrm{~dB}$ & Light & .918 & 8 & .413 \\
& Sound & .901 & 8 & .297 \\
$120 \mathrm{~dB}$ & Light & .927 & 8 & .486 \\
& Sound & .937 & 8 & .586 \\
\hline
\end{tabular}

\section{Fatigue}

Exploratory analysis

$\mathrm{S}-\mathrm{W}$ analysis results show that $p>0.05$. It indicates that the subjects' flicker fusion critical frequency is in normal distribution on 8 noise levels. The specific analysis results of S-W are shown in Table 7.

\section{Sample analysis of t-test}

Table 8 shows that the $t$ value of paired sample test increases with the increase of the noise. Flicker fusion critical frequency decreases as the noise increases. It can be concluded that the worker's fatigue increases with the increase of noise. Table 8 shows that there is a significant difference between the control group and the $70 \mathrm{~dB}$ group and above $70 \mathrm{~dB}$ groups. In other words, the external noise has a significant impact on fatigue from $70 \mathrm{~dB}$.

\section{Prediction of the impact of noise levels on workers' safety working ability}

As can be seen from the above analysis, noise has a significant influence on fatigue, reaction, and attention. In order to find out the relationship between safety behavioral indicators and noise, we took noise level as independent variable and behavior indicators as the dependent variable. The experimental data was subjected to regression analysis. The regression process selects linear, logarithmic, quadratic, power function, and exponential function. The best fit models were selected based on $\mathrm{R}^{2}$. When $\mathrm{R}^{2}$ is greater than 0.9 , the data fitting effect becomes better.

Figures 2, 3, 4 and 5 shows the trend between noise and behavior indicators. Noise is negatively correlated with the attention and reaction, and it is positively correlated with fatigue. When environmental noise level exceeds $70 \sim 80 \mathrm{~dB}$, noise has a significant effect on the subjects' attention, reaction, and fatigue.

It can be seen from Fig. 2 that when the noise level is between 60 and $80 \mathrm{~dB}, \mathrm{Q}$ value decreases slowly with the increase of noise level. When noise level is greater than 
Table 6 Paired sample t-test results for acoustic and optic reaction

\begin{tabular}{|c|c|c|c|c|c|c|c|c|}
\hline & \multicolumn{5}{|c|}{ Pairing Difference } & \multirow[t]{3}{*}{$\mathbf{t}$} & \multirow{3}{*}{$\begin{array}{l}\text { Degree of } \\
\text { Freedom }\end{array}$} & \multirow{3}{*}{$\begin{array}{l}\text { Significant } \\
P \text { (Two-tailed) }\end{array}$} \\
\hline & \multirow[t]{2}{*}{ Average (E) } & \multirow{2}{*}{$\begin{array}{l}\text { Standard } \\
\text { Deviation }\end{array}$} & \multirow{2}{*}{$\begin{array}{l}\text { Standard } \\
\text { Error } \\
\text { Mean }\end{array}$} & \multicolumn{2}{|c|}{ 95\% Confidence Interval for the Difference } & & & \\
\hline & & & & Lower Limit & Upper Limit & & & \\
\hline Sound Control - $60 \mathrm{~dB}$ & -.009 & .045 & .012 & -.035 & .017 & -.765 & 13 & .458 \\
\hline Sound Control - $70 \mathrm{~dB}$ & -.044 & .054 & .014 & -.075 & -.012 & -3.052 & 13 & .009 \\
\hline Sound Control - $80 \mathrm{~dB}$ & -.077 & .088 & .023 & -.128 & -.026 & -3.266 & 13 & .006 \\
\hline Sound Control - $90 \mathrm{~dB}$ & -.136 & .072 & .020 & -.180 & -.092 & -6.785 & 12 & .000 \\
\hline Sound Control - $100 \mathrm{~dB}$ & -.106 & .026 & .009 & -.129 & -.084 & -11.196 & 7 & .000 \\
\hline Sound Control - $110 \mathrm{~dB}$ & -.139 & .030 & .010 & -.165 & -.113 & -12.914 & 7 & .000 \\
\hline Sound Control - $120 \mathrm{~dB}$ & -.198 & .022 & .007 & -.216 & -.179 & -25.282 & 7 & .000 \\
\hline Light Control - $60 \mathrm{~dB}$ & -.001 & .010 & .003 & -.007 & .004 & -.530 & 13 & .605 \\
\hline Light Control - $70 \mathrm{~dB}$ & -.008 & .014 & .004 & -.016 & .001 & -2.337 & 13 & .056 \\
\hline Light Control - $80 \mathrm{~dB}$ & -.060 & .039 & .010 & -.082 & -.037 & -5.778 & 13 & .000 \\
\hline Light Control - $90 \mathrm{~dB}$ & -.093 & .035 & .010 & -.114 & -.072 & -9.524 & 12 & .000 \\
\hline Light Control - $100 \mathrm{~dB}$ & -.087 & .027 & .009 & -.109 & -.065 & -9.220 & 7 & .000 \\
\hline Light Control - $110 \mathrm{~dB}$ & -.134 & .029 & .010 & -.158 & -.110 & -13.255 & 7 & .000 \\
\hline Light Control - $120 \mathrm{~dB}$ & -.181 & .037 & .013 & -.212 & -.150 & -13.957 & 7 & .000 \\
\hline
\end{tabular}

$80 \mathrm{~dB}$, the $\mathrm{Q}$ value decreases sharply. When the noise level reaches $120 \mathrm{~dB}$, the subject's $Q$ value is 0.55 , which is close to the distraction allocation. If the noise level continues to increase, the attention of the subjects will be seriously affected.

As shown in Figs. 3 and 4, with the increase of noise levels, the acousto-optic reaction time increases correspondingly, the comparison between the reaction time to acoustic stimuli and light stimuli shows that the reaction time to the acoustic stimuli varies from $0.40 \mathrm{~s}$ to $0.63 \mathrm{~s}$ and the reaction time to the optic stimuli varies from $0.37 \mathrm{~s}$ to $0.55 \mathrm{~s}$. The reaction time to acoustic stimuli will be longer. Acoustic reaction time becomes significant when the noise is $70 \mathrm{~dB}$, while optic reaction time is 80 $\mathrm{dB}$. It shows that subjects are more sensitive to optic stimuli than acoustic stimuli in noisy environment.

Table 7 Exploratory analysis results of noise group flicker fusion frequency

\begin{tabular}{llll}
\hline $\begin{array}{l}\text { Noise } \\
\text { level }\end{array}$ & Shapiro-Wilk & & \\
\cline { 2 - 4 } & Statistics & df & Significant $\boldsymbol{p}$ \\
\hline Control & .959 & 14 & .701 \\
$60 \mathrm{~dB}$ & .977 & 14 & .952 \\
$70 \mathrm{~dB}$ & .956 & 14 & .654 \\
$80 \mathrm{~dB}$ & .980 & 14 & .977 \\
$90 \mathrm{~dB}$ & .958 & 13 & .730 \\
$100 \mathrm{~dB}$ & .859 & 8 & .118 \\
$110 \mathrm{~dB}$ & .853 & 8 & .103 \\
$120 \mathrm{~dB}$ & .897 & 8 & .273 \\
\hline
\end{tabular}

It can be seen from Fig. 5 that when noise level is lower than $70 \mathrm{~dB}$, the change of flash fusion frequency value is minor. When noise level reaches $70 \mathrm{~dB}$ or more, flash fusion frequency decreases greatly. It shows that different levels of noise have different effects on the fatigue degree. The greater noise level is, the more fatigue the subjects are.

From the analysis of fitting effect as is seen in Table 9, exponential function and quadratic function are most suitable for the modeling of the data in this study. The derivative value of the function indicates the speed of change of the behavior indicators. According to the properties of exponential functions and quadratic functions, the absolute value of derivative of the two functional models continue to increase. Therefore, the greater the noise level is, the faster attention, reaction and fatigue will change, so workers are more prone to accidents in high noise environment.

\section{Discussion}

Unlike most of the previous studies [6, 9-12, 26], which studied the occupational harm of noise on human, this study focused on the influence of different noise levels on miners' safety behavior in underground coal mines and conducted a simulation quantitative experiment of 93 people/hours. Results of this study show that high noise environment significantly affect fatigue, attention, and reaction. Significance analyses reveal that fatigue is the most sensitive to the change of noise and displays a significant change when the noise is above $70 \mathrm{~dB}$. The sensitiveness of reaction and attention are followed by that of fatigue and displays a significant change when 
Table 8 Paired sample t-test results of flicker fusion frequency

\begin{tabular}{|c|c|c|c|c|c|c|c|c|}
\hline & \multicolumn{5}{|c|}{ Pairing Difference } & \multirow[t]{3}{*}{$\mathbf{t}$} & \multirow{3}{*}{$\begin{array}{l}\text { Degree } \\
\text { of Freedom }\end{array}$} & \multirow{3}{*}{$\begin{array}{l}\text { Significant } \\
P \text { (Two-tailed) }\end{array}$} \\
\hline & \multirow[t]{2}{*}{ Average (E) } & \multirow{2}{*}{$\begin{array}{l}\text { Standard } \\
\text { Deviation }\end{array}$} & \multirow{2}{*}{$\begin{array}{l}\text { Standard } \\
\text { Error } \\
\text { Mean }\end{array}$} & \multicolumn{2}{|c|}{ 95\% Confidence Interval for the Difference } & & & \\
\hline & & & & Lower Limit & Upper Limit & & & \\
\hline Control - $60 \mathrm{~dB}$ & .014 & .751 & .200 & -.419 & .448 & .071 & 13 & .944 \\
\hline Control - $70 \mathrm{~dB}$ & .407 & .628 & .167 & .044 & .769 & 2.425 & 13 & .031 \\
\hline Control - $80 \mathrm{~dB}$ & 1.657 & .873 & .233 & 1.152 & 2.161 & 7.100 & 13 & .000 \\
\hline Control - $90 \mathrm{~dB}$ & 2.107 & .864 & .239 & 1.585 & 2.630 & 8.790 & 12 & .000 \\
\hline Control - $100 \mathrm{~dB}$ & 3.050 & .728 & .257 & 2.440 & 3.659 & 11.834 & 7 & .000 \\
\hline Control - $110 \mathrm{~dB}$ & 3.450 & .621 & .219 & 2.930 & 3.969 & 15.712 & 7 & .000 \\
\hline Control - $120 \mathrm{~dB}$ & 4.125 & .686 & .242 & 3.551 & 4.698 & 17.006 & 7 & .000 \\
\hline
\end{tabular}

*In Table 2, 3, 4, 5, 6, 7 and 8: In order to facilitate observation, the data analysis results are marked. If Significant $P(p) \geq 0.05$, gray mark is used, and Significant $P$ $(p)<0.05$, orange mark is used

the noise is above $80 \mathrm{~dB}$. In the noise environment, the sensitivity of optic stimuli is more obvious than that of acoustic stimuli. In this sense, optic stimuli can be used to improve safety systems in noisy environment. Regression analysis results show that noise is negatively related to attention and reaction, and positively related to fatigue.

At the same time, this study has the following shortcomings: (a) The number of subjects in this experiment is small, and the age of the subjects is different from that of the actual miners. (b) Due to the limitation of our experimental conditions, the experiment did not include the influence of the time duration of the noise exposure.
As a fundamental study in the field of coal mine noise, this paper mainly aims to measure the behavioral indicators of subjects affected by noise environment. To address the limitations of the study, we will conduct an in-depth study on the impact of the noise environment on the safety behavior of miners by expanding the sample size and measuring noise duration.

Similar with the previous studies [35-37], this study also found that the safety behavior ability of miners in a high noise environment is significantly lower than that in a low noise environment. However, we found a noise level of $70 \sim 80 \mathrm{~dB}$ starts to affect the safety behavior ability while other researches [35-37] concluded that the

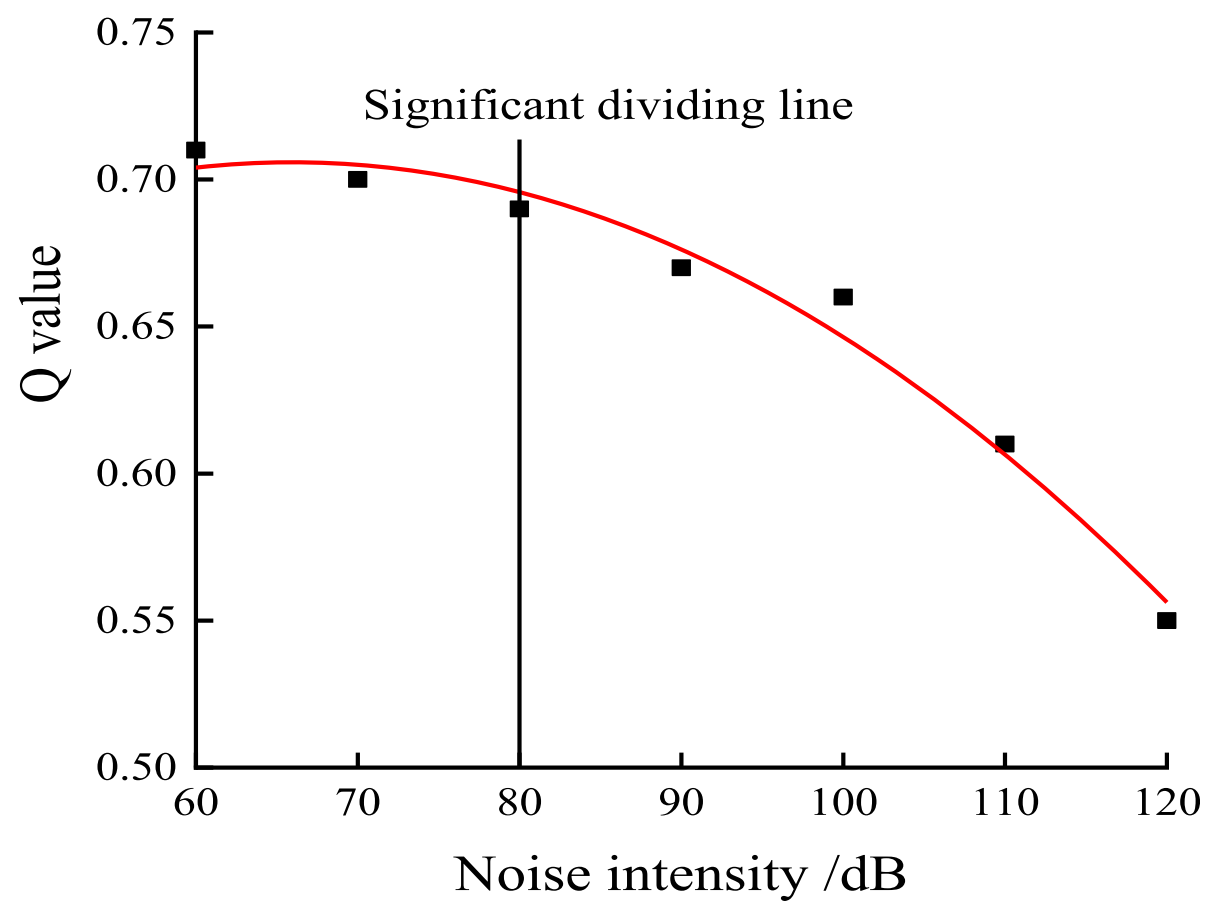

Fig. 2 Relationship between attention distribution $Q$ value and noise levels 


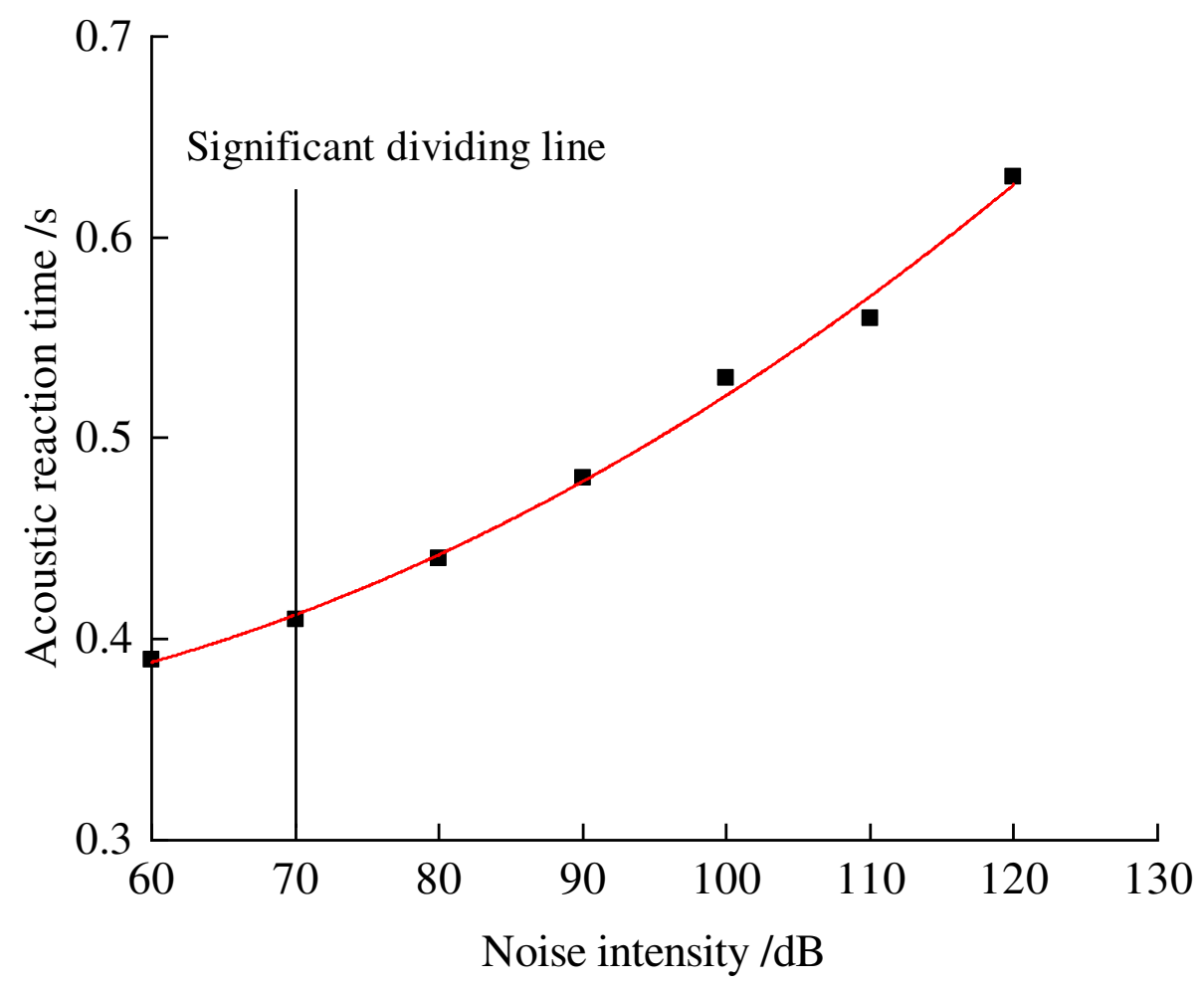

Fig. 3 Relationship between acoustic reaction time and noise levels

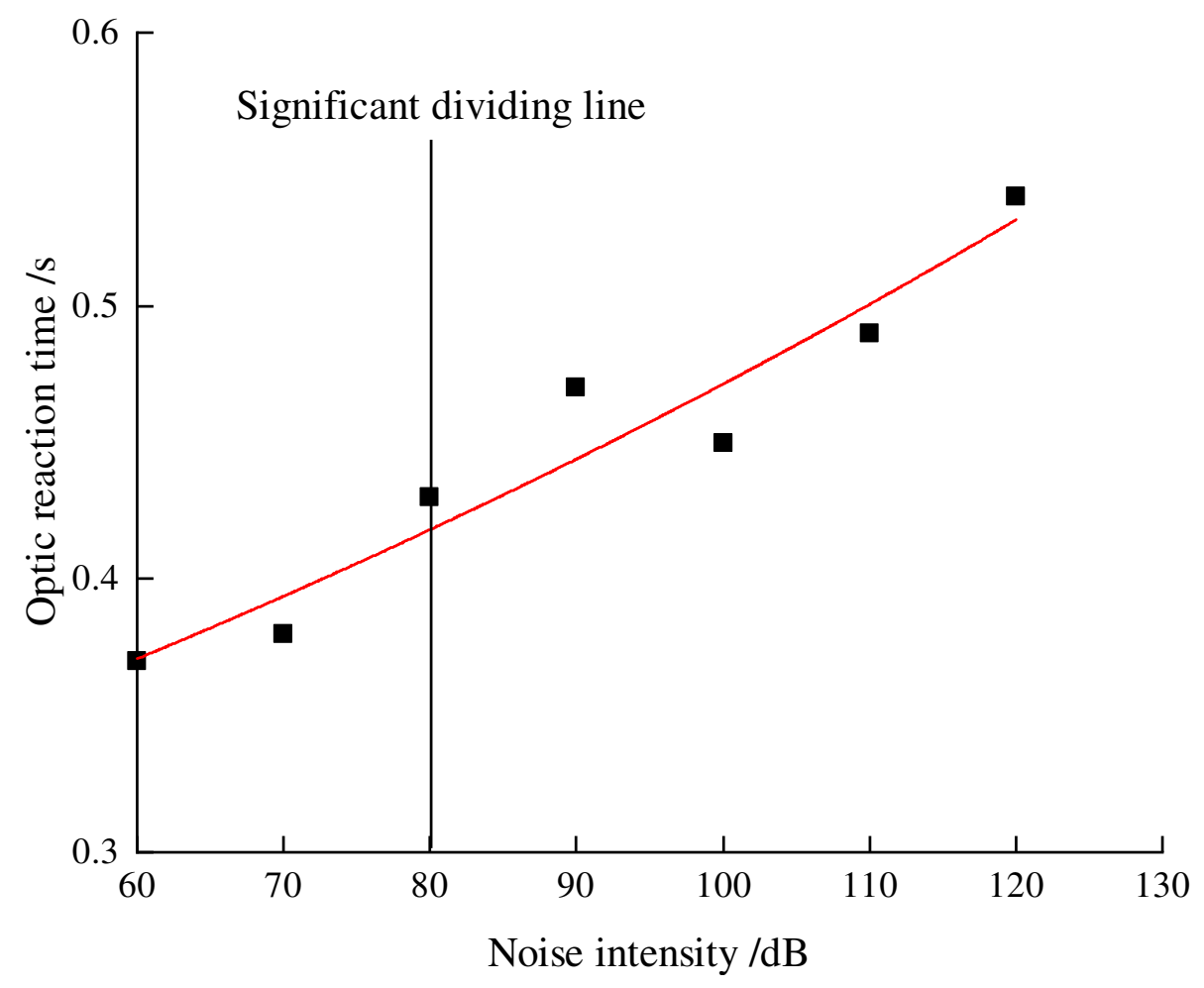

Fig. 4 Relationship between optic reaction time and noise levels 


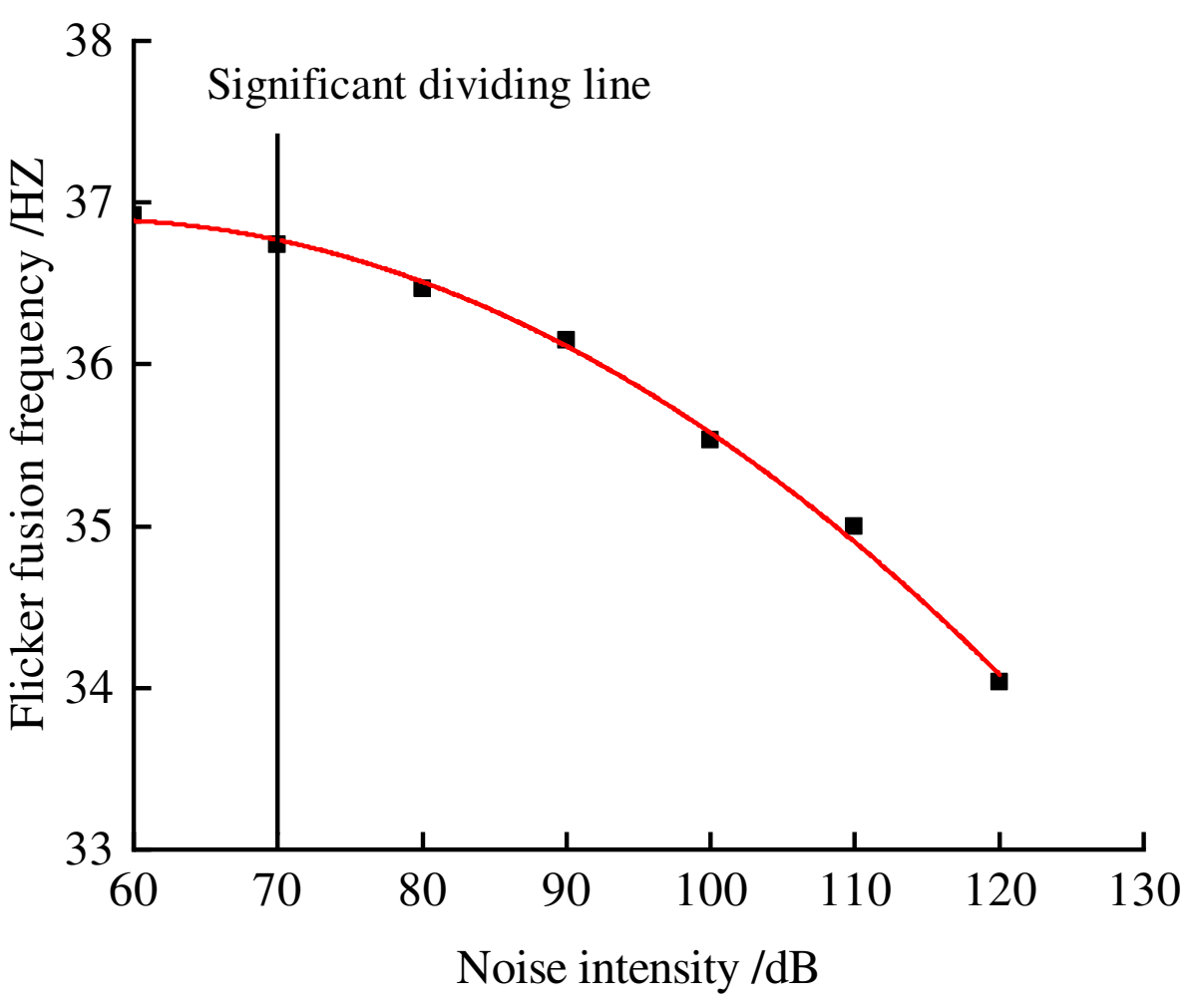

Fig. 5 Relationship between flicker fusion frequency and noise levels

specific noise level that changes significantly is different $(85 \sim 95 \mathrm{~dB})$. The reason for the difference between previous studies and this study may be different sources of noise, different safety behavior indicators, different subjects and different interests (the previous studies focused on physical health, while this study focused on safety behavior). But certain reasons need to be studied in-depth. There are suggested pathways linking long-term exposure to noise environment and human unsafe behavior. In a study by Deng [33], noise affected the physiology and psychology, and then affected human behavior, increasing the probability of safety accidents. Specifically, in the high-noise environment, such effects are manifested as the distraction of attention, the decrease of auditory ability. They lead to auditory and systemic fatigue. In this state, due to the development of protective inhibition, the activity of cerebral cortex cells decreases.

Table 9 Fitting equation of behavior indicators and noise levels

\begin{tabular}{lll}
\hline Behavior index & Regression fitting equation & $\mathbf{R}^{\mathbf{2}}$ \\
\hline Q value & $y=-0.0051 x^{2}+0.0163 x+0.6929$ & 0.9813 \\
Reaction time of sound & $y=0.00003 x^{2}-0.0014 x+0.3701$ & 0.9966 \\
Reaction time of light & $y=0.2587 e^{0.006 x}$ & 0.9241 \\
Flicker fusion frequency & $y=-0.0007 x^{2}+0.079 x+34.668$ & 0.9969 \\
\hline
\end{tabular}

*In formula: $\mathrm{x}$ is the noise level, $\mathrm{R}^{2}$ is the correlation coefficient, indicating the accuracy of the fitting
Accordingly, the conditioned reflex activity is affected, the probability of mis operation increases, and the probability of accident increases.

\section{Conclusion}

This paper selected three safety behavior indicators: attention, reaction, and fatigue, and studied how coal mine noise effects these safe working abilities. The results were shown as follows:Noise can affect the attention, reaction, and fatigue of miners. When the environmental noise is $80 \mathrm{~dB}$ or above, the attention begins to change significantly compared with an environment without noise $(50 \mathrm{~dB})$. When the noise is $70 \mathrm{~dB}$ or above, fatigue level begins to show a significant change compared with an environment without noise $(50 \mathrm{~dB})$. Notably, we found the sensitivity of optic stimuli is more obvious than that of acoustic stimuli: the reaction time to acoustic starts to be statistically significant from $70 \mathrm{~dB}$ while the reaction time to optic starts to be statistically significant from $80 \mathrm{~dB}$. In this sense, optic stimuli can be used to improve safety systems in noisy environment. Results of regression analysis show that attention and reaction is negatively related to noise levels, while fatigue is positively related to noise levels. Taking noise as the independent variable, attention ( $\mathrm{Q}$ value), fatigue (flash fusion frequency), and acoustic reaction time is best fitted by the mathematical model of quadratic function. Optic 
reaction time is best fitted by exponential function. And Figures 2, 3, 4 and 5 shows that compared with the no noise $(50 \mathrm{~dB})$, the greater the noise level increases, the more significantly the subjects' attention, reaction, and fatigue change. It infers that workers are safer in a low noise environment. It is recommended that the noise level in working place is controlled within $70 \sim 80 \mathrm{~dB}$ or below. This way, the inclination of accidents will decrease.

\section{Acknowledgements}

Not Applicable.

\section{Authors' contributions}

$J$ designed the study. $J$ and $Y Q$ written the manuscript. $L Y, Z W$, and $K H$ performed data collection and data analysis. CG performed review and editing of manuscript. All authors read and approved the final manuscript.

\section{Funding}

This work was supported by the Special Fund Projects for Basic Scientific Research Expenses in Central Colleges and Universities (2015QZ04). The funding body played no role in the design of the study and collection, analysis, and interpretation of data and in writing the manuscript.

\section{Availability of data and materials}

The datasets used and/or analysed during the current study are available from the corresponding author on reasonable request.

\section{Ethics approval and consent to participate}

All research procedures were approved prior to the commencement of the study by the China University of mining and technology (Beijing). All participants signed an informed consent form. Our research received ethics approval from China University of Mining and Technology (Beijing) and it conformed to the ethics guidelines of the Declaration of Helsinki.

\section{Consent for publication}

Not Applicable.

\section{Competing interests}

The authors declare that they have no competing interests.

Received: 25 February 2020 Accepted: 28 January 2021

Published online: 09 February 2021

\section{References}

1. Li L, Tian SC, Deng J, Wang L, Li TJ. Study on the coal miners' unsafe behavior: effective factors analysis and control measures. J Xi'an Univ Sci Technol. 2011;31(6):794-8,813. https://doi.org/10.13800/j.cnki.xakjdxxb. 2011.06 .031

2. Law of the People's Republic of China on the Prevention and Control of Environmental Noise Pollution. Xinjiang Farm Res Sci Technol. 2020; 43(08):55-7.

3. Lin BW. Talking about the prevention and control of occupational hazards in coal mine enterprises-noise prevention. Zhong Guo Ke Ji Zong Heng. 2016;005:165.

4. Wang $\mathrm{H}$, Jiang $\mathrm{CL}$, Shi LL. Analysis and countermeasures on underground noise hazards of coal mine. J Saf Sci Technol. 2011;7(12):183-7.

5. 2007 GBZ 2.2. Occupational exposure limits for hazardous agents in the workplace. Part 2:physical agents; 2007.

6. Cheng GY, Chen SJ, Wei ZY, He F. Impact of underground noise on human physiology and psychology. J Xi'an Univ Sci Technol. 2011;31(6):850-3. https://doi.org/10.13800/j.cnki.xakjdxxb.2011.06.044

7. Tian SC, Yang PF, Gao Y, Ma YL. Research on the relationship between noise and miner emotions and intervention countermeasures. Coal Technol. 2017; 36(08):299-301. https://doi.org/10.13301/j.cnki.ct.2017.08.120.

8. Li B. Analysis and control measures against occupational hazards in the coal industry. Ye Jin Gong Ye Chu Ban She: Beijing; 2005. http://niohp.chinacdc. cn/cbw/201211/t20121129_72320.htm
9. Kovalchik PG, Matetic RJ, Smith AK, Bealko SB. Application of prevention through Design for Hearing Loss in the mining industry. J Saf Res. 2008; 39(2):251-4. https://doi.org/10.1016/j.jsr.2008.02.029.

10. Vienneau D, Schindler C, Perez L, Probst-Hensch N, Roeoesli M. The relationship between transportation noise exposure and ischemic heart disease: a meta-analysis. Environ Res. 2015;138:372-80. https://doi.org/10. 1016/j.envres.2015.02.023.

11. Münzel T, Sørensen M, Gori T, Schmidt FP, Rao X, Brook J, et al. Environmental stressors and cardio-metabolic disease: part I-epidemiologic evidence supporting a role for noise and air pollution and effects of mitigation strategies. Eur Heart J. 2017;38(8):550-6. https://doi.org/10.1093/ eurheartj/ehw269.

12. Rojek M, Rajzer MW, Wojciechowska W, Drożdż T, Czarnecka D. Relationship among long-term aircraft noise exposure, blood pressure profile, and arterial stiffness. J Hypertens. 2019. https://doi.org/10.1097/HJH. 0000000000002060.

13. Mariola S-K, Kamil Z. WHO environmental noise guidelines for the European region: a systematic review on environmental noise and permanent hearing loss and tinnitus. Int J Env Res Pub He. 2017;14(10):1139. https://doi.org/10. 3390/ijerph14101139.

14. Shi $L$, Zhang $X$. Research progress on effects of noise on human health. China Occup Med. 2015;42(2):225-8.

15. Basner M, Babisch W, Davis A, Brink M, Clark C, Janssen S, et al. Auditory and non-auditory effects of noise on health. Lancet. 2014;383(9925):1325-32. https://doi.org/10.1016/S0140-6736(13)61613-X.

16. Lie A, Skogstad M, Johannessen HA, Tynes T, Mehlum IS, Nordby KC, et al. Occupational noise exposure and hearing: a systematic review. Int Arch Occup Environ Health. 2016;89(3):351-72. https://doi.org/10.1007/s00420015-1083-5.

17. van den Tillaart-Haverkate M, de Ronde-Brons I, Dreschler WA, Houben R. The influence of noise reduction on speech intelligibility, response times to speech, and perceived listening effort in Normal -hearing listeners. Trends Hear. 2017;21(2):2147483647. https://doi.org/10.1177/2331216517716844.

18. Silva VAR, Guimarães AC, Lavinsky J, Pauna HF, Castilho AM, Crespo AN, et al. Effect of noise exposure on 1,382 metallurgical Workers in Periodic Audiometric Evaluation: a cohort study. Audiol Neurotol. 2020;25(6):309-14. https://doi.org/10.1159/000506894.

19. Wouters NL, Kaanen Cl, Ouden PJD, Schilthuis H, Laat JAPMD. Noise exposure and hearing loss among Brewery Workers in Lagos, Nigeria. Int $J$ Env Res Pub He. 2020;17(8):2880. https://doi.org/10.3390/ijerph17082880.

20. Moroe NF. Occupational noise-induced hearing loss in the mining sector of South Africa: perspectives of occupational health practitioners on how mineworkers are trained. South Afr J Commun Disord. 2020. https://doi.org/ 10.4102/sajcd.v67i2.676.

21. Albizu EJ, Goncalves CGD, Lacerda ABMD, Zeigelboim BS, Marques JM. Noise exposure and effects on hearing in Brazilian fishermen. Work. 2020; 65(4):881-9. https://doi.org/10.3233/WOR-203139.

22. Farooqi ZUR, Sabir M, Latif J, Aslam Z, Ili P. Assessment of noise pollution and its effects on human health in industrial hub of Pakistan. Environ Sci Pollut R. 2020;27(3):1-10. https://doi.org/10.1007/s11356-019-07105-7.

23. Masterson EA, Bushnell PT, Themann CL, Morata TC. Hearing impairment among noise-exposed workers-United States, 2003-2012. Morb Mortal Wkly Rep. 2016:65(15):389-94. https://doi.org/10.15585/mmwr.mm6515a2.

24. Lundberg U, Frankenhaeuser M. Psychophysiological reactions to noise as modified by personal control over noise intensity. Biol Psychol. 1978;6(1):519. https://doi.org/10.1016/0301-0511(78)90006-6.

25. Singh AP, Rai RM, Bhatia MR, Nayar HS. Effect of chronic and acute exposure to noise on physiological functions in man. Int Arch Occup Environ Health. 1982;50(2):169-74. https://doi.org/10.1007/BF00378078.

26. Tian SC, Zhang DT. Effect of high temperature combined noise on Miner's unsafe behavior. Coal Mine Saf. 2019;50(02):241-4. https://doi.org/10.13347/j. cnki.mkaq.2019.02.056.

27. Hessel PA, Sluis-Cremer GK. Occupational noise exposure and blood pressure: Iongitudinal and cross-sectional observations in a Group of Underground Miners. Arch Environ Health. 1994;49(2):128-34. https://doi. org/10.1080/00039896.1994.9937466.

28. Liu J, Xu M, Ding L, Zhang H, Pan L, Liu Q, et al. Prevalence of hypertension and noise-induced hearing loss in Chinese coal miners. J Thorac Dis. 2016; 8(3):422-9. https://doi.org/10.21037/jtd.2016.02.59.

29. Tian SC, Liang Q, Wang L, Wu LJ, Yin LY. Research on the relationship between the noise and miner behavior safety and prevention-control 
countermeasures. J Xi'an Univ Sci Technol. 2015;35(05):555-60. https://doi. org/10.13800/j.cnki.xakjdxxb.2015.0505.

30. Fan $L Y$, Jin LZ, Huang ZL, Gao N. Experimental study on noise of mine emergency rescue capsule. Coal Technol. 2016;35(03):210-2. https://doi.org/ 10.13301/j.cnki.ct.2016.03.083.

31. You B, Tang X, Shi SL, Liu HQ, Li RQ, Luo WK. Simulated experimental study of noise over human safety behavior. Miner Eng Res. 2017;32(04):14-9. https://doi.org/10.13582/j.cnki.1674-5876.2017.04.003.

32. Kou M. Experimental research on the difference of miners' safety behavior. Min Saf Environ Prot. 2018;45(01):74-6. https://doi.org/10.3969/j.issn.10084495.2018.01.017.

33. Deng CJ. Analysis of the noise hazards prevention and control underground coal mine. Energy Energy Conserv. 2015;11:48-9. https://doi.org/10.16643/j. cnki.14-1360/td.2015.11.023.

34. Yu GL, Wang QL, Yang ZL. Environmental psychology. People's Educ Press. 2000.

35. Wang JG, Fu W, Wang YQ. Study on the effects of different levels of noise on miners' physiological indexes and behavioral abilities. Min Saf Environ Prot. 2019;46(01):99-103. https://doi.org/10.3969/j.issn.1008-4495.2019.01.022.

36. Mundorff JS. Effects of speech signal type and attention on acceptable noise level in elderly, hearing-impaired listeners; 2011. https://commons.lib. jmu.edu/diss201019/43

37. Jing GX, Lu PF, Zhao PF, Wang YS. Experimental study on the influence of coal mine noise on people's attention. J Saf Sci Technol. 2017;13(10):164-8. https://doi.org/10.11731/j.issn.1673-193x.2017.10.027.

38. Xu HQ, Zhou H, Ren YL. Subjective evaluation on noise sound quality with considerations of driver's response time and attention. Automot Eng. 2013; 35(08):740-3. https://doi.org/10.19562/j.chinasae.qcgc.2013.08.015.

39. Li J, Wu LL, Tong YH. Research on the relationship between noise and unsafe behaviors of employees based on SPSS. J North China Univ Sci Technol. 2017;14(05):82-5. https://doi.org/10.3969/j.issn.16727169.2017.05.015

40. Liao B, Teng HM. Optimization of test scheme for correlation analysis of flash fusion critical frequency and optical phase stimulation intensity. Chin J Ergon. 2016;22(02):58-61. https://doi.org/10.13837/j.issn.1006-8309. 2016.02.0011.

41. Zhang MZ. Association between fatigue and safety performance of construction workers. Tsinghua University; 2014.

42. Li M, Jia HQ, Li KW, Niu YW, Yao DF, Jing WX. Effect of noise level on unsafe behavior of humans. China Saf Sci J. 2017;27(03):-19, 24. https://doi.org/10. 16265/j.cnki.issn1003-3033.2017.03.004.

43. Wang CX, Lu SL. Experimental study on influence to safety attention by noise. J Saf Sci Technol. 2016;12(03):160-4. https://doi.org/10.11731/j.issn. 1673-193x.2016.03.029.

44. Shalini P, Brooks LJ, Carolyn D, Hall WA, Suresh K, Lloyd RM, et al. Recommended amount of sleep for pediatric populations: a consensus statement of the American Academy of sleep medicine. J Clin Sleep Med. 2016;12(06):785-6. https://doi.org/10.5664/jcsm.5866.

\section{Publisher's Note}

Springer Nature remains neutral with regard to jurisdictional claims in published maps and institutional affiliations.

Ready to submit your research? Choose BMC and benefit from:
- fast, convenient online submission
- thorough peer review by experienced researchers in your field
- rapid publication on acceptance
- support for research data, including large and complex data types
- gold Open Access which fosters wider collaboration and increased citations
- maximum visibility for your research: over 100M website views per year
At BMC, research is always in progress.
Learn more biomedcentral.com/submissions

